\title{
Distinct Mechanosensitive Properties of Capsaicin-Sensitive and -Insensitive Sensory Neurons
}

\author{
Liam J. Drew, John N. Wood, and Paolo Cesare \\ Department of Biology, University College London, London, WC1E 6BT United Kingdom
}

\begin{abstract}
Mechanical stimulation of the somata of cultured neonatal rat dorsal root ganglia (DRG) neurons evoked inward cationic currents that displayed distinct properties between different subsets of cells. The presumptive nociceptor population, defined by capsaicin sensitivity, showed higher thresholds for the induction of an inward current and lower peak currents than other mechanosensitive neurons. A subset of capsaicin-sensitive IB4-positive sensory neurons was refractory to mechanical stimulation. All mechanically activated currents were blocked by gadolinium $\left(\mathrm{IC}_{50} \sim 8 \mu \mathrm{M}\right)$ and ruthenium red $\left(\mathrm{IC}_{50} \sim 3 \mu \mathrm{M}\right)$. Disruption of the actin cytoskeleton by acute application of 10
\end{abstract}

Dorsal root ganglia (DRG) contain the cell bodies of sensory neurons. Most DRG neurons respond to mechanical stimulation and can be broadly classified as low threshold mechanoreceptors and high threshold nociceptors. Mechanical stimulation is thought to directly activate mechanosensitive ion channels expressed on the receptive endings of these neurons. However, the molecular identity of these ion channels remains uncertain, and their physiological and pharmacological properties are poorly understood (Lewin and Stucky, 2000).

Recent studies suggest a role for members of the acid-sensing ion channel (ASIC) family in mechanosensation. Animals lacking the gene for $\mathrm{ASIC} 2 / \mathrm{BNC1}$ show reduced firing frequencies in rapidly adapting and, to a lesser extent, slowly adapting mechanoreceptors in response to mechanical stimulation (Price et al., 2000). Null mutant ASIC3/dorsal root acid-sensing ion channel (DRASIC) mice show diminished mechanosensitivity of A-fiber mechanonociceptors and an enhanced response of rapidly adapting mechanoreceptors (Price et al., 2001). However, to date there is no evidence that ASICs can be directly gated by pressure.

Receptors normally found on the peripheral terminals of DRG neurons in vivo are often expressed on the cell bodies of these neurons in vitro. For example, high temperatures $\left(>42^{\circ} \mathrm{C}\right)$ applied to somata of sensory neurons in culture activate an inward cationic current (Cesare and McNaughton, 1996). These currents are mediated by the capsaicin receptor (VR1) that is expressed on nociceptor terminals (Tominaga et al., 1998). Therefore the

\footnotetext{
Received Jan. 22, 2002; revised March 21, 2002; accepted March 25,2002.

This work was supported by The Wellcome Trust and Medical Research Council. We thank Mark Baker for his helpful comments and advice and Chris Gadd for assistance with data analysis.

Correspondence should be addressed to John Wood, Department of Biology, Medawar Building, University College London, Gower Street, London, WC1E 6BT UK. E-mail: j.wood@ucl.ac.uk.

P. Cesare's present address: Dipartimento di Biologia Cellulare e dello Sviluppo, Universita' degli studi di Roma "La Sapienza," Piazzale Aldo Moro 5, 00185 Rome, Italy.

Copyright (C) 2002 Society for Neuroscience $\quad 0270-6474 / 02 / 220001-\bullet \$ 15.00 / 0$
}

$\mu \mathrm{M}$ cytochalasin B inhibited currents much more effectively in capsaicin-insensitive (61\%) than capsaicin-sensitive neurons (20\%). Extracellular calcium also attenuated mechanosensitive currents and to a greater degree in capsaicin-insensitive neurons than capsaicin-sensitive neurons. These data demonstrate that the somata of different types of cultured sensory neurons have distinct mechanosensitive phenotypes that retain properties associated with nerve terminal mechanosensors in vivo.

Key words: mechanosensation; ion channel; DRG; capsaicin; nociception; IB4; ASIC

somata of cultured sensory neurons were examined as a system for the study of mechanically activated (MA) currents.

McCarter et al. (1999) have shown previously that cultured DRG neuron somata respond to mechanical stimulation with an inward cationic current. In this study we extend these findings to show that there is diversity among the responses of DRG neurons to pressure in vitro that correlates with aspects of their in vivo properties.

\section{MATERIALS AND METHODS}

Cell culture. Neonatal Sprague Dawley rats were decapitated, and 25-35 DRG were taken from each animal. DRG were enzymatically digested in $1 \mathrm{mg} / \mathrm{ml}$ collagenase D (Roche), and neurons were isolated by mechanical trituration. Cells were cultured on poly-L-lysine- and laminin-coated dishes in the presence of NGF $(100 \mathrm{ng} / \mathrm{ml})$ and used the day after preparation. Superior cervical ganglia $(\mathrm{SCG})$, from postnatal day $(\mathrm{P})$ 14-21 rats, were prepared in the same way.

Electrophysiology. Medium-sized neurons (diameter $>30 \mu \mathrm{m}$ ) or small neurons (diameter $<30 \mu \mathrm{m}$ ) with cell bodies that were not in contact with those of other neurons were selected for recording. Recordings were made using an Axopatch 200B amplifier at a holding potential of -70 $\mathrm{mV}$. Data were acquired at $20 \mathrm{kHz}$ using PClamp software (Axon Instruments).

Experiments were performed in the perforated-patch configuration. MA currents recorded using this technique were stable for considerably longer (up to $30 \mathrm{~min}$ ) than those recorded using the conventional wholecell configuration. The pipette solution contained (in mM): 110 methane-

This article is published in The Journal of Neuroscience, Rapid Communications Section, which publishes brief, peerreviewed papers online, not in print. Rapid Communications are posted online approximately one month earlier than they would appear if printed. They are listed in the Table of Contents of the next open issue of JNeurosci. Cite this article as: JNeurosci, 2002, 22:RC228 (1-5). The publication date is the date of posting online at www.jneurosci.org.

http://www.jneurosci.org/cgi/content/full/6459 
sulfonic acid, $30 \mathrm{KCl}, 1 \mathrm{MgCl}_{2}$ and $10 \mathrm{HEPES}, \mathrm{pH} 7.35$ (pH was corrected using $\mathrm{KOH}$; final $\mathrm{K}^{+}$concentration $140 \mathrm{~mm}$ ); $200 \mu \mathrm{g} / \mathrm{ml}$ amphotericin B was added immediately before recording. Series resistance was typically $5-10 \mathrm{M} \Omega$ and was compensated for by $40-60 \%$. Standard extracellular solution contained (in mM): $140 \mathrm{NaCl}, 4 \mathrm{KCl}, 2$ $\mathrm{CaCl}_{2}, 1 \mathrm{MgCl}_{2}, 4 \mathrm{D}$-glucose (added fresh), and 10 HEPES, pH 7.4. Solutions were changed in $\sim 2-3 \mathrm{sec}$ using a system whereby multiple tubes flowed into a single output that perfused the cell.

Neurons were mechanically stimulated using a heat-polished glass electrode (tip diameter $\sim 5-6 \mu \mathrm{m}$ ) positioned at an angle of $60^{\circ}$ to the surface of the culture dish. Pressure was applied using a computercontrolled Piezo-electric crystal drive (Burleigh). The probe was positioned such that a $10 \mu \mathrm{m}$ movement did not visibly contact the cell but a $12 \mu \mathrm{m}$ stimulus produced an observable membrane deflection. A $12 \mu \mathrm{m}$ probe movement was defined as a $2 \mu \mathrm{m}$ stimulation, $14 \mu \mathrm{m}$ was defined as a $4 \mu \mathrm{m}$ stimulus, and so on. Stimulation was at a rate of $0.5 \mu \mathrm{m} / \mathrm{msec}$, and the stimulus lasted $200 \mathrm{msec}$. To assess the mechanical sensitivity of a cell, a series of six mechanical steps in $2 \mu \mathrm{m}$ increments were applied at $15 \mathrm{sec}$ intervals, which was sufficient time for full current recovery. For other experiments, cells that showed a reproducible response to mechanical stimuli $(>200 \mathrm{pA}$ stimulated at $20 \mathrm{sec}$ intervals) were selected for further experimentation.

Gadolinium $\left(\mathrm{GdCl}_{3}\right)$, amiloride, ruthenium red, cytochalasin $\mathrm{B}$, and gentamicin (all from Sigma) were dissolved in extracellular solution. Concentration-inhibition curves for ruthenium red and $\mathrm{Gd}^{3+}$ were fitted using the Langmuir equation. Capsaicin (Calbiochem) was dissolved in DMSO $(10 \mathrm{~mm})$ and applied at $1 \mu \mathrm{M}$ after mechanical stimulation of the cell (a clear, inward current $>50 \mathrm{pA}$ was defined as a positive response). Capsaicin was used to distinguish presumptive nociceptive and nonnociceptive neurons, because at P1-2 there is no clear correlation between action potential properties and DRG neuronal phenotype (Ritter et al., 2000). pH 5.2 solution was also used to stimulate neurons; this was applied before capsaicin.

IB4 labeling was achieved by incubating the cells in IB4-Alexa 488 (Molecular Probes) $3 \mu \mathrm{g} / \mathrm{ml}$ in standard external solution for $10 \mathrm{~min}$ before recording. Cells were then washed in external solution three times. For control experiments responses were recorded, and then $4.5 \mu \mathrm{g}$ of IB4-Alexa in $100 \mu \mathrm{l}$ was added to the $1.5 \mathrm{ml}$ bath solution for $10 \mathrm{~min}$ before perfusion of the cells with control solution.

\section{RESULTS}

Perforated-patch recordings from cultured DRG neurons have demonstrated that most of these cells are mechanically sensitive. In $92 \%$ (66 of 72) of medium-sized neurons tested, mechanical stimulation evoked an inward current. Of cells that responded, the majority $(86 \%$; 57 of 66 ) had evoked currents characterized by an initially rapidly adapting (RA) phase followed at high stimulation intensities by a sustained component (Fig. 1A, right). The remaining 14\% (9 of 66) of neurons expressed MA currents that were slowly adapting (SA) $\left(t_{0.5}\right.$ of adaptation $\left.>200 \mathrm{msec}\right)$ (Fig. 1A, left). Mechanical stimulation of SCG neurons did not evoke an inward or outward current $(n=10)$.

Division of medium-sized neurons into presumptive nociceptive and non-nociceptive populations according to their sensitivity to capsaicin $(1 \mu \mathrm{M})$ revealed clear differences between these groups. Of those neurons that did not respond to capsaicin (Caps-), 95\% (38 of 40) responded to mechanical stimulation, whereas $88 \%$ (28 of 32) of capsaicin-sensitive (Caps + ) neurons responded. All neurons that displayed SA MA currents were insensitive to capsaicin and considered a separate population for analysis.

The three groups showed differing sensitivities to mechanical stimulation (two-way ANOVA, repeated measures; $p<0.001$ ) (Fig. $1 B$ ). The most striking difference was in the amplitude of RA MA currents between Caps + and Caps - populations of cells (Fig. $1 B)$. In Caps - cells with RA MA currents, currents were consistently much larger than those in the Caps+ population (Fig. 1B). The amplitude of SA MA currents showed large variability but was intermediate between RA groups. At the maximum stimulation the mean amplitudes of MA currents were as follows: Caps-, RA
A
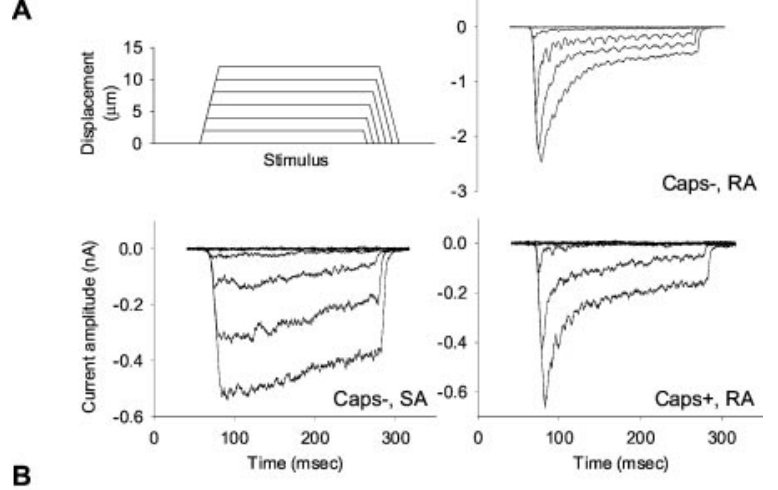

B

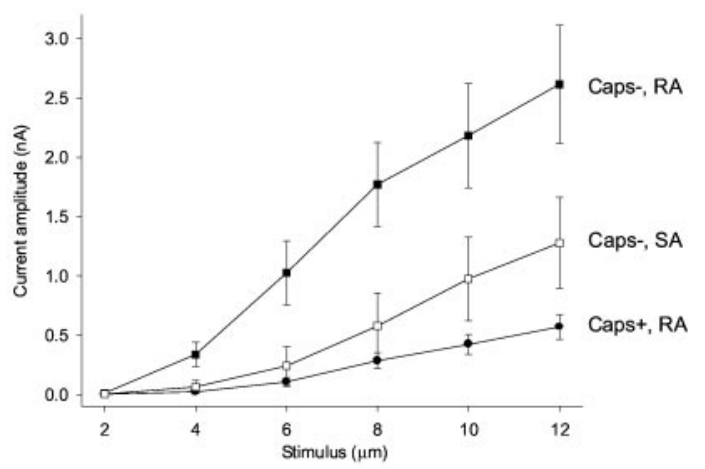

C

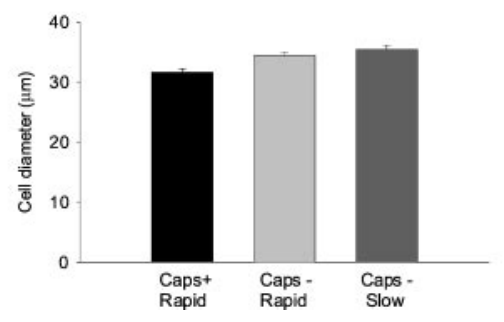

Figure 1. Subpopulations of DRG neurons demonstrate different levels of mechanosensitivity. $A$, Representative traces from three subpopulations of DRG neurons. Right panel, Top and bottom traces show RA currents from Caps - and Caps + neurons, respectively. The left panel shows an SA current; note the differences in scale. $B$, The mean amplitude of RA MA currents in Caps - neurons $(\boldsymbol{\square}, n=31)$ was significantly larger than in Caps + neurons $(\mathbf{O}, n=32)$. MA currents of Caps - neurons with SA responses $(\square, n=9)$ were intermediate (two-way, repeated measures ANOVA; $p=0.001$ ). $C$, Caps + neurons (black bar; diameter $31.7 \pm 0.6$ $\mu \mathrm{m})$ were significantly smaller than Caps - neurons with either SA (dark gray bar; $35.5 \pm 0.7 \mu \mathrm{m}$ ) or RA (light gray bar; $34.4 \pm 0.6 \mu \mathrm{m}) \mathrm{MA}$ currents by 10.8 and $8.0 \%$, respectively $(t$ test; $p<0.001$ and $p=0.002$, respectively).

$2.62 \pm 0.50 \mathrm{nA} ;$ Caps - , SA $1.28 \pm 0.38 \mathrm{nA}$; and Caps $+0.57 \pm$ $0.11 \mathrm{nA}$. All cells that responded to peak mechanical stimulation with currents $>2 \mathrm{nA}$ were Caps - (16 RA, 2 SA).

At low levels of stimulation, significantly more Caps - than Caps + neurons displayed MA currents, consistent with a lower threshold of mechanical activation. With a $4 \mu \mathrm{m}$ displacement, $47 \%$ of Caps - , RA neurons responded with currents $>50 \mathrm{pA}$, which was significantly more than Caps+ neurons $(13 \%)$ and Caps -, SA neurons $(11 \%)\left(\chi^{2} ; p<0.05\right)$.

Differences in mechanosensitivity were not attributable to cell size (Fig. 1C). Although Caps + cells (diameter $31.7 \pm 0.6 \mu \mathrm{m}$ ) were significantly smaller than Caps - neurons with RA MA currents $(34.4 \pm 0.7 \mu \mathrm{m})$, the difference was only $8.0 \%$ ( $t$ test; $p=$ 0.02). This small difference is unable to account for the large differences in current amplitude. Furthermore, MA current ampli- 

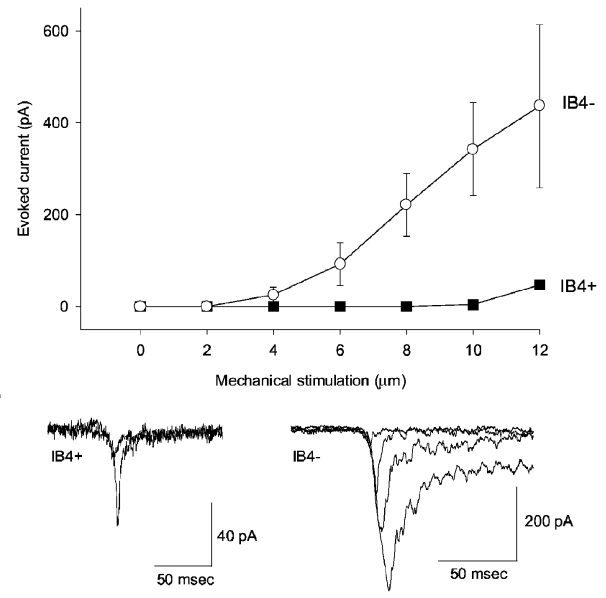

C

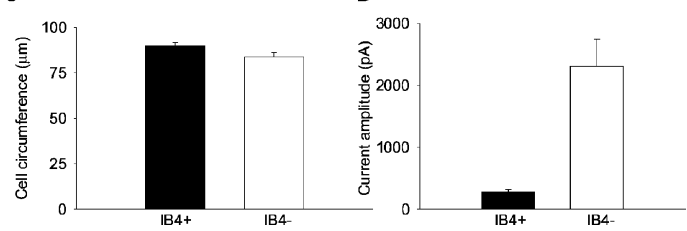

Figure 2. IB4+ and IB4- nociceptors respond differently to mechanical stimulation. $A$, The mean amplitude of MA currents in IB4-, Caps+ neurons $(O, n=8)$ was significantly larger than those seen in IB4+, Caps + neurons $(\square, n=9)$ (two-way, repeated measures ANOVA; $p<$ $0.001)$. IB $4+$, Caps + neurons were mostly refractory to mechanical stimulation, whereas the responses seen in IB4-, Caps + small neurons were similar to those seen in medium-sized Caps + neurons. $B$, Representative traces from an IB4+ and an IB4- cell. $C$, There was no significant difference in the diameter of IB4+ (black bar; $28.6 \pm 0.6 \mu \mathrm{m})$ and IB4 - (white bar; $26.7 \pm 0.7 \mu \mathrm{m})$ neurons ( $t$ test; $p=0.053)$. D, The mean amplitude of responses evoked by $1 \mu \mathrm{M}$ capsaicin was significantly larger in IB4 - cells $(2306.3 \pm 437.8 \mathrm{pA} ; n=8)$ than in IB4+ cells $(301.1 \pm 41.4 \mathrm{pA} ; n=9)(t$ test; $p<0.001)$.

tude did not correlate with cell diameter either overall or within groups.

We examined the mechanically evoked responses of smaller capsaicin-sensitive neurons and distinguished cells according to whether they bound IB4, an isolectin that labels a subpopulation of nociceptive neurons (Molliver et al., 1997). We found that the responses of Caps + , IB4- cells did not significantly differ from those of medium-sized Caps + neurons. However, those Caps + neurons that were labeled with IB4 showed little or no response to mechanical stimulation (Fig. $2 A, B$ ). There was large variation in the size of MA currents in Caps+/IB4- cells, but all were mechanically sensitive. It was not possible to determine whether IB4+ neurons respond to higher levels of mechanical stimulation, because stimuli $>12 \mu \mathrm{m}$ are liable to dislodge the cell from the substrate or disrupt the seal. To control for the possibility that IB4 blocks the underlying ion channels, mechanical responses were recorded in six Caps + neurons before staining with IB4. Of these, two that were unlabeled responded to a $10 \mu \mathrm{m}$ mechanical displacement with currents $>100 \mathrm{pA}$ and to a $12 \mu \mathrm{m}$ stimulus with currents of 254 and 389 pA, respectively. Conversely, of the four neurons that were subsequently labeled with IB4, two did not respond to mechanical stimulation, and of the other two the maximal evoked current was $160 \mathrm{pA}$. There was also a large difference in the amplitude of currents evoked by $1 \mu \mathrm{M}$ capsaicin between these two populations; IB4+ neurons had a mean current amplitude of $0.30 \pm 0.04 \mathrm{nA}$, whereas IB4- cells had a larger mean
A
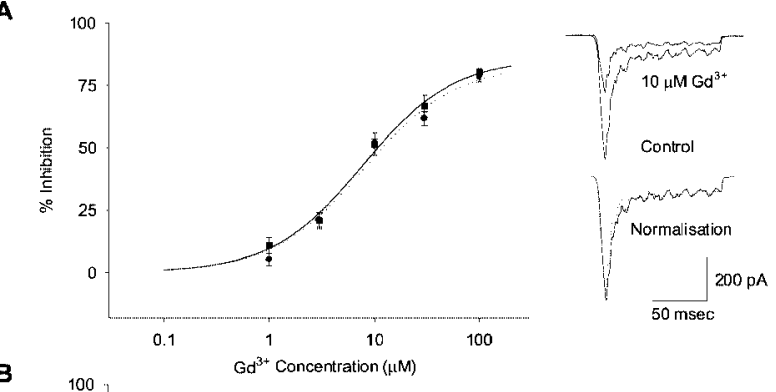

B
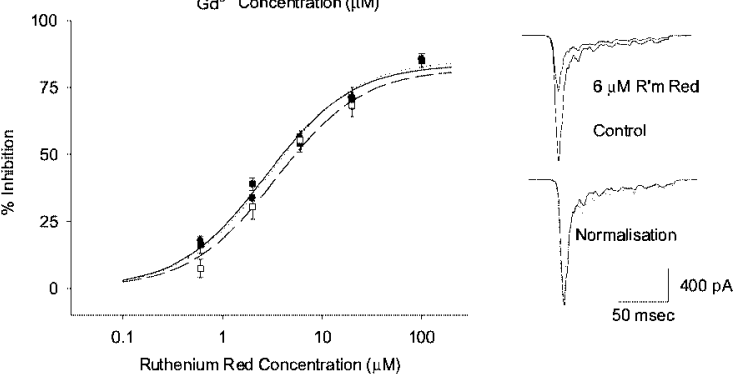

c
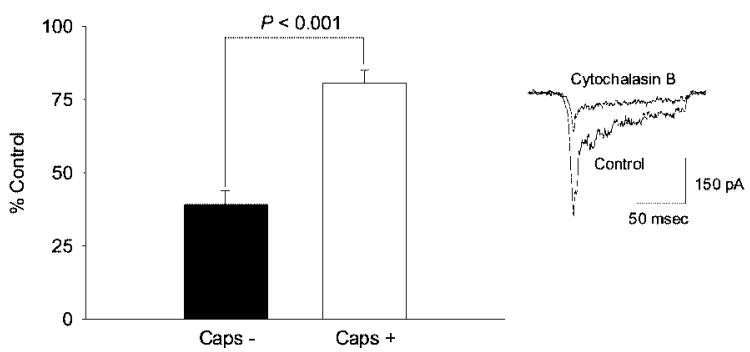

Figure 3. Ruthenium red, gadolinium, and cytochalasin B inhibit MA currents. A, Left, The concentration dependence of block of RA MA currents in Caps $+(\mathbf{O})$ and Caps $-(\boldsymbol{\square})$ neurons by $\mathrm{Gd}^{3+}(1-100 \mu \mathrm{M})$ was indistinguishable. The derived $\mathrm{IC}_{50}$ values were $7.99 \mu \mathrm{M}(\mathrm{Caps}+)$ and $7.77 \mu \mathrm{M}(\mathrm{Caps}-) . n=3-6$ for each data point. Right, Typical trace of inhibition by $\mathrm{Gd}^{3+}$. Also shown is the trace normalized to peak current showing equal blockade of transient and sustained components of the currents. $B$, Ruthenium red $(0.6-100 \mu \mathrm{M})$ blocked RA and SA MA currents with similar efficacy. Derived $\mathrm{IC}_{50}$ values were $2.97 \mu \mathrm{M}(\mathrm{Caps}+$, $\mathrm{RA} ; 0), 2.71 \mu \mathrm{M}$ (Caps-,RA; $\mathbf{-}$ ), and $3.45 \mu \mathrm{M}$ (SA; $\square) . n=2-7$ for each data point. Right, Typical trace of inhibition by ruthenium red and currents normalized to peak current. C, Left, Cytochalasin B $(10 \mu \mathrm{M})$ had an inhibitory effect on MA currents that was more pronounced in Capsneurons. In Caps - neurons (black bar), MA currents were inhibited by $60.9 \pm 4.7 \%(n=6)$ (significantly less than control; $p<0.001)$ and by $19.5 \pm 4.5 \%$ in Caps + cells (white bar; significantly less than control; $p<$ 0.05). Comparison of the drug effect in the two groups showed that the effect of cytochalasin B was significantly greater in the Caps- neurons $(p<0.001)$. Right, Typical trace of inhibition by cytochalasin $\mathrm{B}$ in a Caps - neuron.

response of $2.31 \pm 0.44 \mathrm{nA}(t$ test; $p<0.001)$ (Fig. $2 C)$. IB4 + and IB4- cells were not significantly different in size (Fig $2 D)$.

$\mathrm{Gd}^{3+}$ and ruthenium red both reversibly blocked MA currents with $\mathrm{IC}_{50}$ values of $<10 \mu \mathrm{M}$ (Fig. 3). The blockade of RA MA currents in Caps - and Caps + cells by $\mathrm{Gd}^{3+}(1-100 \mu \mathrm{M})$ was very similar (Fig. 3A): the derived $\mathrm{IC}_{50}$ values were $7.99 \mu \mathrm{M}$ (Caps + ) and $7.77 \mu \mathrm{M}$ (Caps-). Likewise the blockade of MA currents by ruthenium red $(0.6-100 \mu \mathrm{M})$ was similar in all three subpopulations of neurons (Fig. 3B). Derived $\mathrm{IC}_{50}$ values were $2.97 \mu \mathrm{M}$ (Caps+, RA), $2.71 \mu \mathrm{M}$ (Caps-, RA), and $3.45 \mu \mathrm{M}$ (SA). Amiloride up to $500 \mu \mathrm{M}$ and gentamicin up to $100 \mu \mathrm{M}$ did not block MA currents.

The role of the cytoskeleton in the activation of mechanically evoked responses was examined by acutely applying the inhibitor of actin polymerization cytochalasin $\mathrm{B}(10 \mu \mathrm{M})$ (Fig. $3 C)$. This 
A

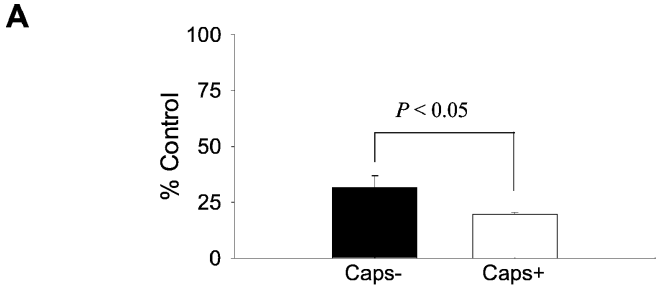

B

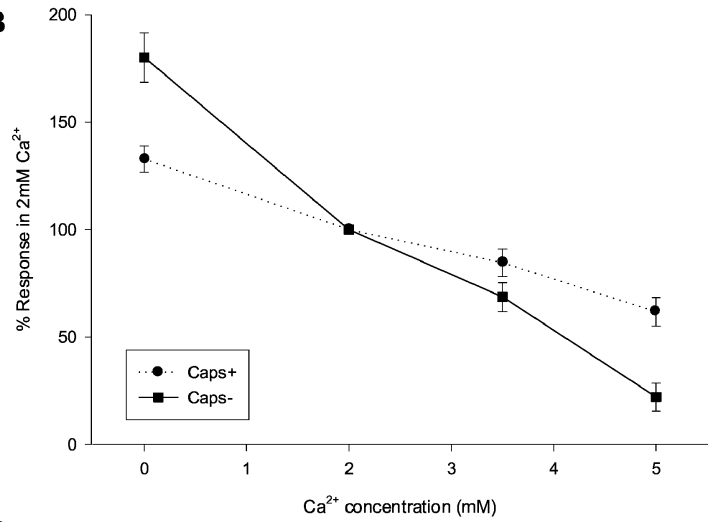

C

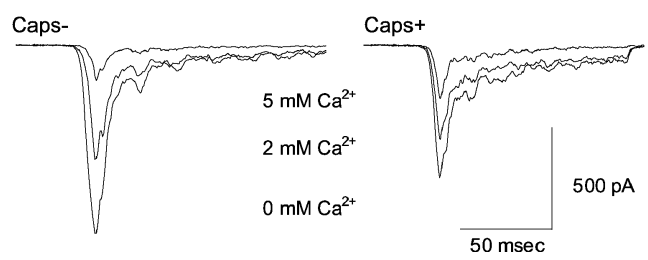

Figure 4. External $\mathrm{Ca}^{2+}$ had a modulatory effect on MA current amplitude. $A$, Removal of $\mathrm{Na}^{+}$from the external solution (control: $\left[\mathrm{Ca}^{2+}\right]=$ $2 \mathrm{mM}$ ) caused a reduction in MA currents of $80.3 \pm 0.9$ and $68.3 \pm 5.1 \%$ in Caps + (white bar; $n=5$ ) and Caps-(black bar; $n=5$ ) neurons, respectively. The level of reduction was significantly different between the two groups $(t$ test; $p<0.05)$. $B$, The amplitude of MA currents was largest in nominally $\mathrm{Ca}^{2+}$-free solution, and increasing external $\mathrm{Ca}^{2+}$ concentration inhibited MA currents. The effect of $\mathrm{Ca}^{2+}$ was significantly greater in Caps - neurons than in Caps + neurons (two-way ANOVA; $p<0.01)(n=3-8$ for each data point). $C$, Representative traces from a Caps- (left panel) and Caps + (right panel) neuron showing MA currents evoked in nominally 0,2 , and $5 \mathrm{mM} \mathrm{Ca}^{2+}$.

significantly inhibited MA currents in Caps + neurons by $19.5 \pm$ $4.5 \%(n=6 ; t$ test; $p<0.05)$ and in Caps - neurons by $60.9 \pm$ $4.7 \%(n=6 ; p<0.001)$. Notably, the effect of cytochalasin B was substantially larger in Caps- neurons ( $t$ test; $p<0.001)$.

The ionic basis of MA RA currents was investigated using ionic substitution experiments. Replacement of external $\mathrm{Na}^{+}$with the impermeant cation $N$-methyl-D-glucamine led to a large reduction in the amplitude of all currents (Fig. 4A). However, there was a significantly larger reduction in the amplitude of currents in Caps + cells $(80.3 \pm 0.9 \%)$ than in Caps - cells $(68.3 \pm 5.1 \%)(t$ test; $p<$ $0.05)$. Manipulation of the external $\mathrm{Ca}^{2+}$ concentration revealed that MA current amplitude was inversely correlated to $\mathrm{Ca}^{2+}$ concentration (Fig. 4B,C). This effect was significantly more pronounced in $\mathrm{Caps}^{-}$neurons than in Caps + neurons (two-way ANOVA; $p<0.05$ ). In nominally $\mathrm{Ca}^{2+}$-free external solution, current amplitude increased, relative to $2 \mathrm{mM} \mathrm{Ca}^{2+}$, by $80.1 \pm 11.5$ and $32.8 \pm 6.1 \%$ in Caps - and Caps + cells, respectively. Consistent with a blocking effect of $\mathrm{Ca}^{2+}$, increasing $\mathrm{Ca}^{2+}$ concentration to $5 \mathrm{~mm}$ led to a reduction in current amplitude of $38.3 \pm 6.6$ and $78.0 \pm 6.6 \%$ in Caps + and Caps - cells, respectively.

The putative mechanosensory ASICs are activated by low $\mathrm{pH}$ (Waldmann and Lazdunski, 1998). However, we found that neither the amplitudes nor the kinetics of MA currents were related to those of proton-gated currents $(n=14)$. Interestingly, the amplitude of currents evoked by mechanical stimulation with an external $\mathrm{pH}$ of 5.2 or 6.4 did not differ from those recorded at $\mathrm{pH} 7.4(n=$ $10)$.

\section{DISCUSSION}

Presumptive non-nociceptive and nociceptive neurons, defined by their capsaicin sensitivity, showed clear differences in their mechanosensitive properties. These differences were consistent with the in vivo phenotypes of DRG neurons. Caps- neurons expressed larger mechanically evoked responses than Caps + neurons, and a large proportion of these cells responded to low levels of stimulation, whereas the majority of Caps + neurons responded only to higher levels of pressure. In vivo non-nociceptive mechanoreceptors detect multiple forms of pressure change and are characterized by low thresholds to mechanical activation. Conversely, nociceptors, have high thresholds of mechanical activation (Lewin and Stucky, 2000).

Approximately one-fourth of capsaicin-insensitive neurons responded to mechanical stimulation with SA currents. This mixture of response kinetics is of interest given the diversity of non-nociceptive mechanoreceptor subtypes seen in vivo (Koltzenburg et al., 1997). The identity of the cells with SA MA currents is unclear. They could correspond to slowly adapting mechanoreceptors or, given their intermediate mechanosensitivity, to $\mathrm{A} \delta$ neurons. Not all nociceptive neurons are capsaicin sensitive [ $\sim 75 \%$ are VR1 positive (Guo et al., 1999)]; therefore, the Caps- population must include some nociceptive neurons that may account for those cells that did not respond or responded weakly to mechanical stimulation.

There was a clear divergence in mechanical sensitivity between IB4+ and IB - cells in the Caps+ population. IB4+ cells were mostly refractory to mechanical stimulation, whereas IB4-/ Caps + cells responded to pressure. However, it is known that IB4+ neurons respond to high levels of mechanical stimulation in vivo (Gerke and Plenderleith, 2001). It is possible that IB4+ cells have higher mechanical thresholds that were not reached because of the danger of detaching the cell from the substrate or losing the seal. Another possible explanation is that these neurons respond to high levels of pressure via the release of a chemical mediator. One candidate for this role is ATP. Approximately 90\% of IB4+ neurons display P2X3 or P2X2/3 currents (Burgard et al., 1999), and there is evidence that $\mathrm{P} 2 \mathrm{X} 3$ receptors are central to mechanosensation in the bladder through activation by mechanically evoked ATP release (Vlaskovska et al., 2001). The observed differences in mechanical sensitivity and in the amplitude of capsaicin-evoked responses between IB4+ and IB4- neurons also extend findings by Stucky and Lewin (1999) showing differences in heat sensitivity and voltage-activated sodium currents between these populations.

DRG MA currents are blocked by $\mathrm{Gd}^{3+}$ and ruthenium red. $\mathrm{Gd}^{3+}$ blocks mechanosensitive ion channels in a range of systems (Hamill and Martinac, 2001); it blocks DRG MA currents with an $\mathrm{IC}_{50}$ of $\sim 8 \mu \mathrm{M}$ in both Caps + and Caps - neurons. Interestingly, there is evidence that $\mathrm{Gd}^{3+}$ antagonizes ASIC3/2a-mediated currents (Babinski et al., 2000) and also inhibits transient low-pH evoked responses in DRG (our unpublished observations). Ruthenium red, a known antagonist of VR1 (Caterina et al., 1997), blocked MA currents with an $\mathrm{IC}_{50}$ of $\sim 3 \mu \mathrm{M}$ for both populations of RA currents and SA currents. $\mathrm{IC}_{50}$ values for ruthenium red obtained here are at least 10 -fold higher than those found for 
VR1 (Dray et al., 1990). The similarity in the pharmacology of MA currents among different subpopulations of neurons suggests that closely related ion channels mediate these currents. DRG MA currents are not blocked by gentamicin, suggesting they are not mediated by the ion channels that underlie cochlear mechanotransduction (Jaramill and Hudspeth, 1991).

MA currents are primarily mediated by $\mathrm{Na}^{+}$ions, but there is a significant contribution from $\mathrm{Ca}^{2+}$, more so in the Capsneurons. Furthermore, $\mathrm{Ca}^{2+}$ had a modulatory effect on the amplitude MA currents. Up to $5 \mathrm{~mm}$, MA current amplitude was inversely related to the external $\mathrm{Ca}^{2+}$ concentration. Moreover, currents in Caps - cells appeared more sensitive to changes in external $\mathrm{Ca}^{2+}$ levels. These data suggest that $\mathrm{Ca}^{2+}$ has a blocking effect on the underlying ion channels. This may be attributable to slow permeation by $\mathrm{Ca}^{2+}$ effectively blocking the passage of $\mathrm{Na}^{+}$. Similarly, $\mathrm{Ca}^{2+}$ ions have been demonstrated to block $\mathrm{Na}^{+}$channels where they bind to a site within the pore (Campbell and Hille, 1976).

It is proposed that the mechanically activated currents observed here are caused by activation of mechanosensitive ion channels that underlie mechanotransduction at the sensory terminal in vivo. However, it is likely that the cytoarchitecture of the sensory terminal, the surrounding extracellular matrix, and association of the terminal with auxiliary cell types (e.g., Pacinian corpuscles, Merkel cells, etc.) will modify the transmission of forces to the transduction site (Loewenstein and Skalak, 1966). All or some of these factors may well affect the kinetics of mechanically evoked responses in situ. We found that the actin cytoskeleton plays an important role in channel gating by treating cells with cytochalasin B. Inhibition of actin polymerization inhibited MA currents in Caps+ neurons and to a much greater degree in Caps - neurons. This suggests that differential tethering of mechanosensitive ion channels to the cytoskeleton may be important in setting the sensitivity of the channels.

Recent data suggest that members of the ASIC family of ion channels play a critical role in mechanosensation (Price et al., 2000, 2001). The ionic basis of MA currents is similar to those of some proton-activated ASIC currents (Waldmann and Lazdunski, 1998). Furthermore, Immke and McCleskey (2001) have shown recently that ASIC-mediated currents in ischemia-sensing neurons are modulated in a manner similar to MA currents by changes in external $\mathrm{Ca}^{2+}$ (and $\mathrm{Mg}^{2+}$ ) concentration, and Berdiev et al. (2001) have shown that $\mathrm{Ca}^{2+}$ blocks recombinant ASIC2 channels. We found that the amplitude of MA currents is not correlated with the amplitude of low $\mathrm{pH}$-evoked responses in DRG and that MA currents are not regulated by acidification of the external solution. However, ASIC2a (Price et al., 2000; Garcia-Anoveros et al., 2001) and ASIC3 (Price et al., 2001) are present on the endings of $\mathrm{A} \beta$ fibers in vivo, and these neurons are not activated by low $\mathrm{pH}$. This observation raises the possibility that ASICs may be able to exist in a proton-insensitive state that is mechanosensitive (Welsh et al., 2002). Those ion channels that are mechanosensitive may not respond to protons because of their inclusion in a complex of molecules that masks the protonbinding site. These two states may display differing sensitivities to amiloride blockade.

In conclusion, these results confirm that cultured DRG neurons are a system in which mechanotransduction can be studied and have revealed a number of physiological and pharmacological properties of mechanosensitive currents. Further analysis of this system should enable the molecular identity of DRG mechanosensitive ion channel components to be established

\section{REFERENCES}

Babinski K, Catarsi S, Biagini G, Seguela P (2000) Mammalian ASIC2a and ASIC3 subunits co-assemble into heteromeric proton-gated channels sensitive to $\mathrm{Gd}^{3+}$. J Biol Chem 275:28519-28525.

Berdiev BK, Mapstone TB, Markert JM, Gillespie GY, Lockhart J, Fuller CM, Benos DJ (2001) pH alterations "reset" Ca2 + sensitivity of brain $\mathrm{Na}+$ channel 2, a degenerin/epithelial $\mathrm{Na}+$ ion channel, in planar lipid bilayers. J Biol Chem 276:38755-38761.

Burgard EC, Niforatos W, van Biesen T, Lynch KJ, Touma E, Metzger RE, Kowaluk EA, Jarvis MF (1999) P2X receptor-mediated ionic currents in dorsal root ganglion neurons. J Neurophysiol 82:1590-1598.

Campbell DT, Hille B (1976) Kinetic and pharmacological properties of the sodium channel of frog skeletal muscle. J Gen Physiol 67:309-323.

Caterina MJ, Schumacher MA, Tominaga M, Rosen TA, Levine JD, Julius D (1997) The capsaicin receptor: a heat-activated ion channel in the pain pathway. Nature 389:816-824.

Cesare P, McNaughton P (1996) A novel heat-activated current in nociceptive neurons and its sensitization by bradykinin. Proc Natl Acad Sci USA 93:15435-15439.

Dray A, Forbes CA, Burgess GM (1990) Ruthenium red blocks the capsaicin-induced increase in intracellular calcium and activation of membrane currents in sensory neurones as well the activation of peripheral nociceptors in vitro. Neurosci Lett 110:52-59.

Garcia-Anoveros J, Samad TA, Zuvela-Jelaska L, Woolf CJ, Corey DP (2001) Transport and localization of the DEG/ENaC ion channel $\mathrm{BNaC} 1 \alpha$ to peripheral mechanosensory terminals of dorsal root ganglia neurons. J Neurosci 21:2678-2686.

Gerke MB, Plenderleith MB (2001) Binding sites for the plant lectin Bandeiraea simplicifolia I-isolectin $\mathrm{B}(4)$ are expressed by nociceptive primary sensory neurones. Brain Res 911:101-104.

Guo A, Vulchanova L, Wang, J Li X, Elde R (1999) Immunocytochemical localization of the vanilloid receptor 1 (VR1): relationship to neuropeptides, the $\mathrm{P} 2 \mathrm{X} 3$ purinoceptor and IB4 binding sites. Eur J Neurosci 11:946-958.

Hamill OP, Martinac B (2001) Molecular basis of mechanotransduction in living cells. Physiol Rev 81:685-740.

Immke DC, McCleskey EW (2001) Lactate enhances the acid-sensing $\mathrm{Na}+$ channel on ischemia-sensing neurons. Nat Neurosci 4:869-870.

Jaramill F, Hudspeth AJ (1991) Localization of the hair cell's transduction channels at the hair bundle's top by iontophoretic application of a channel blocker. Neuron 7:409-420.

Koltzenburg M, Stucky CL, Lewin GR (1997) Receptive properties of mouse sensory neurons innervating hairy skin. J Neurophysiol 78:1841-1850.

Lewin GR, Stucky CL (2000) Sensory neuron mechanotransduction: regulation and underlying molecular mechanisms. In: Molecular basis of pain transduction (Wood JN, ed), pp 129-148. New York: Wiley.

Loewenstein WR, Skalak R (1966) Mechanical transmission in a Pacinian corpuscle. An analysis and a theory. J Physiol (Lond) 182:346-378.

McCarter GC, Reichling DB, Levine JD (1999) Mechanical transduction by rat dorsal root ganglion neurons in vitro. Neurosci Lett 273:179-182.

Molliver DC, Wright DE, Leitner ML, Parsadanian AS, Doster K, Wen D, Yan Q, Snider WD (1997) IB4-binding DRG neurons switch from NGF to GDNF dependence in early postnatal life. Neuron 19:849-861.

Price MP, Lewin GR, McIlwrath SL, Cheng C, Xie J, Heppenstall PA, Stucky CL, Mannsfeldt AG, Brennan TJ, Drummond HA, Qiao J, Benson CJ, Tarr DE, Hrstka RF, Yang B, Williamson RA, Welsh MJ (2000) The mammalian sodium channel BNC1 is required for normal touch sensation. Nature 407:1007-1011.

Price MP, McIlwrath SL, Xie J, Cheng C, Qiao J, Tarr DE, Sluka K, Brennan T, Lewin GR, Welsh MJ (2001) The DRASIC cation channel contributes to the detection of cutaneous touch and acid stimuli in mice. Neuron 32:1071-1083.

Ritter AM, Woodbury CJ, Albers K, Davis BM, Koerber HR (2000) Maturation of cutaneous sensory neurons from normal and NGFoverexpressing mice. J Neurophysiol 83:1722-1732.

Stucky CL, Lewin GR (1999) Isolectin B(4)-positive and -negative nociceptors are functionally distinct. J Neurosci 19:6497-6505.

Tominaga M, Caterina MJ, Malmberg AB, Rosen TA, Gilbert H, Skinner K, Raumann BE, Basbaum AI, Julius D (1998) The cloned capsaicin receptor integrates multiple pain-producing stimuli. Neuron 21:531-543.

Vlaskovska M, Kasakov L, Rong W, Bodin P, Bardini M, Cockayne DA, Ford AP, Burnstock G (2001) P2X3 knock-out mice reveal a major sensory role for urothelially released ATP. J Neurosci 21:5670-5677.

Waldmann R, Lazdunski M (1998) H(+)-gated cation channels: neuronal acid sensors in the NaC/DEG family of ion channels. Curr Opin Neurobiol 8:418-424.

Welsh MJ, Price MP, Xie J (2002) Biochemical basis of touch perception: mechanosensory function of DEG/ENaC channels. J Biol Chem 277:2369-2372. 